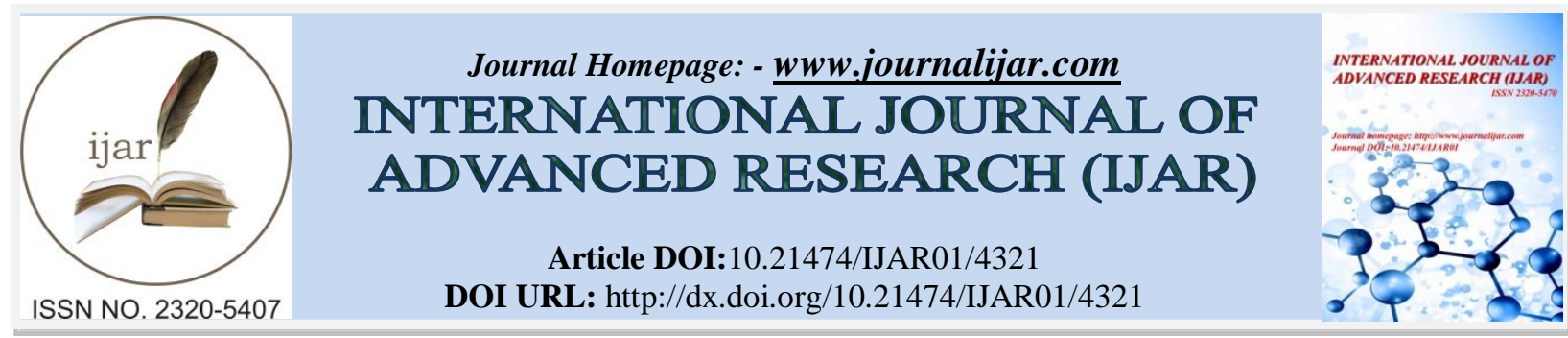

RESEARCH ARTICLE

\title{
RURAL MICROFINANCE DEVELOPMENT IN DIGITAL AND SOCIAL PLATFORM,THINK-TANK TECHNOLOGIES APPLYING TO RURAL MICROFINANCE
}

Ph.D.(c) Otilia Manta.

The School of Advanced Studies of the Romanian Academy, Department of Economics, Sociology and Law.

\section{Manuscript Info}

\section{Manuscript History}

Received: 23 March 2017

Final Accepted: 28 April 2017

Published: May 2017

Key words:-

microfinance, economics, sustainable development.

\section{Abstract}

The purpose of the paper: The paper aims to analyze the impact that digitization has in the development of rural microfinance. We want to underline that the rural micro financing comprise to provide a range of financial services such as savings, credit, payments and insurance for individuals, households and businesses (both agricultural and nonagricultural) in rural areas. On this topic, I have a previous research like "Microfinance, active factor in the social and financial inclusion" which deals whit the fact that we are in the midst of the biggest revolution in information and communication in history. I also mention my paper about "The role of microfinance in sustainable rural development" where I say, among others, that the social inclusion and financial progress are the results of digitization trend of the financial sector with a major impact on financial and non-banking institutions. Creating new distribution models (networks of external agents, banks without branch network), the emergence of new opportunities for customer access and management of back-office are just some of the challenges that microfinance sector has passed through on a continue process of innovation and adaptation and last, but least, I mention another personal work, Financing instruments in eradicating poverty, where I discuss about the agricultural cooperative like an autonomous association with an unlimited number of members with variable capital, which operate economic, technical and social $\mathrm{n}$ the private interests of its members. The present work, like the previous ones, have both, the theoretical and practical component, by presenting examples of best practice. They also are based on personal experience gained in over 10 years of activity in the field of rural areas development.

Key results: The main findings and recommendations are summarized as follows: the stage of development and the complexity of microfinance as globally action decisively influence the variables of financial management, the terms of their specific problems and the nature of our solutions; each type of space defines the microfinance need targeted on specific financial situation of the one in need of microfinance, prompting the objectives, issues and means of action.

Value: Microfinance is estimated that, depending on the complexity of the activities funded, must achieve optimal combination of funding

Corresponding Author:-Ph.D.(c) Otilia Manta.

Address:-The School of Advanced Studies of the Romanian Academy, Department of Economics, 
sources and presented their destination, having as a final objective the socio-economic development of small business. More orientation microfinance in Romania think should be in agreement with the 4Ps of Agenda 2030 "People; Planet; Prosperity; Peace".

Copy Right, IJAR, 2017,. All rights reserved.

\section{Introduction:-}

Any company for aces achieve its objectives in the short, medium or long interacts with his or her social, economic, natural. From a microfinancial standpoint, the company relationship with its environment can be formalized and appealing to the concept of microfinancial networks.

In this way it can reflect a financial structure at micro identifying interconnections between autonomous entities, recognized and identified legal, economic, social.

On the other hand, microfinancial area is a monetary representation of all the other areas that can be identified and defined in society, particularly in the economy and can be considered a set of specific microfinancial interconnections with defining characteristics that distinguish them with the new digital tecnologies. Mirofinancial capacity is dual, presenting two often contradictory stances: all entities, channels, collection of stocks and flows, on the one hand and all entities, channel, placement of stocks and flows. In this context we intend to analyze financial network components and a better delimitation of the risks that may occur in such types of networks.

\section{Materials and Methods:-}

Regarding the methodology of research on financial enviroment, complexity and diversity of the issues addressed have required the use of methods, techniques, tools, and procedures of scientific investigation and interpretation to which it's attached particular importance:

$\checkmark$ Documentation, namely, accessing and studying general and specialized bibliography, domestic and foreign, state approach to knowledge issues investigated financial enviroment and scientific substantiation of the research.

$\checkmark \quad$ The rational method, used as an instrument of knowledge, reflection, analysis, organization, and ongoing scientific research approach.

$\checkmark \quad$ The integration of forms, methods, and logic operations research carried out through the use of analysis and synthesis, abstraction and concretization, comparison, generalization, and systematization.

$\checkmark \quad$ The statistical methods, through the use of descriptive statistics and statistical analysis.

$\checkmark \quad$ The observation method, carried out systematically and analytically.

$\checkmark$ Discussions with experts from institutions and national and international institutions, but also the beneficiaries of financial products and services.

$\checkmark$ Data analysis and interpretation, using graphs, tables, and figures to highlight various developments in financial environment.

Using the classic instruments of scientific research, based on analysis and synthesis, induction and deduction, general and particular, and adding modern methods, authors achieved substantial and pertinent analyses and studies on financial environment main ways, both internationally and especially national. Contributions of authors on investigated issue are highlighted during the research work and theoretical and applicative significance value resulting from the conclusions and proposals that they have formulated and promoted.

The research results are presented using formulas, tables, figures, and graphs. The theoretical information needed for the research was taken from literature and specialized works in the field of financial environment investigated, from home and abroad. Statistical information and concrete data on how financial environment works were taken from reports and statistics of institutes involved in financial environment in the country and abroad as well as to public bodies and private specialist.

This method of analysis provides a more rigorous substantiation of the decision-making process and also maximum reduction in uncertainty. 


\section{Results and Discussions:- Mobil Banking:-}

Every day we relate to the past, present and future we face the fact that we are in the midst of the biggest revolution in information and communication in history. This revolution is reflected even in the poorest segments of the population as reported by the World Bank Report: $20 \%$ of households, nearly 7 in 10, have a mobile phone. According to the same report, more than $40 \%$ of the world population has access to internet. We are living a paradox; the poorest households are more receptive to mobile phones than have access to sewerage service or running water supply. We must take advantage of rapid technological change to make the world more prosperous and inclusive and support the social inclusion through innovative solutions. Microfinance is a tool adapted to current digital revolution. For many people, the current rise of access to digital technologies brings more choices and more convenience. Through the process of social and financial inclusion, microfinance is a real financing mechanism to reach the poor and disadvantaged. The new mobile banking technologies enable vulnerable groups (women, disabled, etc.) to participate more easily in the labour market, as entrepreneurs in the process of telework (online) or outsourcing business. The World Bank estimates that today, more than 16 million people are served by 7,000 microfinance institutions worldwide. Here are some standard microfinance services: credit, savings accounts, money transfer, insurance. Microcredit is one of the services offered by microfinance institutions. The principle of microcredit is to provide small loans to entrepreneurs and those who do not have access to traditional bank loans. We also need to remember that microcredit is not similar to microfinance! With these micro-credits, micro-projects can be developed, thus providing jobs and supporting the local economy. Microcredit is booming, mainly in developing countries. The experts of CGAP (Consultative Group to Assist the Poor) says that means that about 500 million families benefiting from such small loans making possible new business. Some principles that summarize a century and a half of practice was set in 2004 by CGAP and adopted by the G8 leaders at the G8 summit of 10 June 2004:

1. Poor people need not just loans but also by way of savings, insurance and money transfer services; 2 . Microfinance must be useful to poor households: helping them to increase the revenue, purchase goods and/or can cushion against external shocks;

2. "Microfinance can pay for itself", grants from donors and government are scarce and uncertain, as such, to reach large numbers of poor people, microfinance must pay for itself;

3. Microfinance means building permanent local institution;

4. Microfinancing means to integrate the financial needs of the poor in the central financial system of a country;

5. "The task of government is to enable financial services, not to provide them.";

6. "Donor funds should complement private capital market, not compete with it";

7. Donors should focus on capacity building;

8. Microfinance should measure performance and to present both, the financial and social sectors. From here we could also conclude that microfinance is seen as a tool for socio-economic development and cannot be regarded as a charity!

\section{Microfinance and the digital world - when the consumer becomes "visible"}

In a world that is changing almost overnight fueled of the latest communication technologies, the financial sector has no chance to avoid this veritable digital tsunami. A very interesting report from 2014 says that "in many emerging markets, the majority of the population lives outside urban centers without easy access to infrastructure like banking, transport, electricity, and roads. This represents a huge potential customer base in communities where mobile money is the only real competitor to cash. Extensive market research in other industries suggests that rural customers tend to have stronger brand loyalty than their urban counterparts, making them a valuable market segment. Despite the potential size and loyalty of the rural market, evidence suggests most mobile money service providers have yet to expand their services beyond urban centers. Delivering commercially sustainable services to rural areas poses several challenges, which are more or less acute in different markets: more widely dispersed populations, lower literacy levels, less access to basic infrastructure, and lower and often sporadic household incomes. Understanding the scope and magnitude of the challenges will help providers be more strategic about extending the reach of their mobile money services and adapt their approach to the specific market context. The expansion of mobile money into non-urban areas has thus far tended to be a gradual diffusion of services beyond urban centers, rather than a strategic effort by providers to tailor services to meet the needs of rural customers. A more strategic approach could help providers extend services both in advanced mobile money markets, where growth in saturated urban areas is stagnant, and in markets with limited urban market potential where commercial success is dependent upon expansion into rural areas. (e.g.:Jennifer Frydrych and HegeAschim, October 2014). 


\section{Big Data, Small Credit:-}

Here is another concept we face in the new digital world: "big data, small credit"! The Digital Revolution and Its Impact on the Emerging Market Consumers! report underline that "Technological advances in credit assessment are poised to deliver huge impact by bringing formal, accessible, and affordable credit to hundreds of millions of aspiring middle-class consumers in emerging markets. At the forefront of this change is a burgeoning new field that we're calling "Big Data, Small Credit" (BDSC). Around the world, many emerging-market consumers remain severely limited in their access to formal financial services, particularly unsecured credit. In India alone, in 2014, more than 400 million people borrowed money - but fewer than one in seven were approved for a formal loan. Indeed, this experience of being "invisible" to formal lenders is prevalent among billions of "thin file" or "no file" consumers living in nearly all of today's emerging markets. But these consumers may not remain "invisible" to formal lenders for long, thanks in part to their rising use of Technology" (e.g: Arjuna Costa, Anamitra Deb, and Michael Kubzansky, 2014). Every time these individuals make a phone call, send a text, browse the Internet, engage social media networks, or top up their prepaid cards, they deepen the digital footprints they are leaving behind. These digital footprints are helping to spark a new kind of revolution in lending. In the last few years, a cluster of fast-emerging and innovative firms has begun to use highly predictive technologies and algorithms to interrogate and generate insights from these footprints. These BDSC firms are using varied forms of nontraditional data-from mobile call data records and bill payments to Internet browsing patterns and social media behavior - to create a new way to assess consumer risk, determine the creditworthiness of previously "invisible" consumers, and consequently offer convenient, quicker, and often cheaper loans to the previously underserved.

\section{A new generation for a new financial environment:-}

GAFA is an acronym for Google, Apple, Facebook, and Amazon - the 4 most powerful American technology companies. Usage of the term "GAFA" is increasingly common in Europe. The acronym, originally from France, is used to identify the 4 companies as a group. Already we speak about generation GAFA as being composed of those using almost exclusive the services of four companies mentioned. The truth is that change the way consumers see financial services, customer service and shopping. Having almost nothing to do with banking, these tech giants are now directing the pace of innovation across the whole industry and redefining the expectations, putting banks on fire with their rapid pace of transformation. While an average consumer doesn't really notice the transition, professionals have to face the reality and take the challenge that these tech people have suddenly imposed on finance professionals. It was natural in this situation that financial institutions to find out how this new environment - and his followers - acts opposite to the services they offer. Just because shifting consumer trends create new opportunity for financial providers. Consumer behaviors and expectations are shifting in ways that will challenge financial services providers to rethink how they service their customers-and even transform their distribution models. Accenture Financial Services Global Distribution \& Marketing Consumerproduce a study that gathered the views of nearly 33,000 financial services consumers - including banking, insurance and investment advisory customersacross 18 markets. The research identified valuable insights about how customers want to interact with financial providers in future, and where digital innovation must play its part. But it also suggests that providers who can both deliver a compelling new digital service model, and retain traditional values around trust and service, will be best placed for the competitive battleground ahead. (e.g. Accenture, 2017). Some very interesting conclusions can be found here. For many consumers, collectively known as GAFA, are attractive alternatives to traditional financial providers. $140 \%$ of respondents would consider banking with Google or Amazon. This is even higher in markets such as the United States, where 50\% would be willing to make this switch. $36 \%$ of respondents would consider buying insurance from an online service provider, such as Google or Amazon. 46\% of respondents would consider purchasing investment advisory services from an online service provider. Also, three distinct consumer personas emerged within the research findings, each with specific characteristics linked to what they value most from their financial providers, what drives their loyalty and how they would like their providers to embrace digital innovation. The key drivers of loyalty are cost; customer service (defined by high quality and responsiveness); trust (particularly as it relates to acting in the customers' best interest and to protecting data) and the appetite or willingness to consider new digital models. The varying needs and priorities of these groups provide insight into how financial providers may need to reshape their proposition, both to secure the loyalty of existing customers and to reach out to new consumers. So, there are nomads - a highly digitally active group, ready for a new model of delivery; hunters searching for the best deal on price and quality seekers which are looking for high quality, responsive service and data protection. For sure, it is good to know also the sector response.

The GAFA Banking Approach is "to remain central in the lives of consumers while developing new revenue streams, banks need to evolve their business models by turning their attention to their own portfolio of businesses as 
well as to the next generation business opportunities. The goal is to quickly develop a viable response to emerging digital disruptors while managing strategic risk to avoid the loss of revenues to those disruptors. The key here is the interaction between "GO Digital" and "BE Digital" agendas, in which the former is about the businesses of focus, and the latter is about enablement". (e.g. Accenture, 2016)

\section{Digital Finance in Romania:-}

The importance of the realities of rural areas facing by small farmers including low education levels (according to statistics provided by the National Institute of Statistics) and the lack of access to modern financial instruments according to size and their requirements. These conditions means that people involved in developing new models for microfinance institutions must to create new and innovative solutions for funding the needs for small farmers. The existing communication technologies offer us new opportunities for the rural microfinance by reducing business costs. The new microfinance facilities have great potential to address the risks faced by small farmers. In addition, the combination of financial services with non-financial services such as technical support services, marketing and financial consulting offers new opportunities for small farmers to increase their productivity and income and the integration of theirs production in a complete value chains. Finally, from the micro level to the macro level, it is necessary to create an enabling environment for the development of policies and a legal framework for the implementation of rules and regulations. The progress of financial inclusion is the result of digitization trend of the financial sector with a major impact on financial institutions. Creating new distribution models (networks of external agents, banks without branch network, e.g.), the emergence of new opportunities for customer access and management of back-office are just some of the challenges that microfinance sector has passed through a continue innovation and adaptation. The phenomenon of "microfinance" has created new opportunities for customers: easy management of household savings, revenue collection, payment of bills and taxes. Using it muststill become more concrete and consistent in Romania. The customers should be educated to master these new digitized tools. It is indisputable that a revolution is taking place! In the context of the financial crisis, microfinance continues to grow, offering new opportunities in digital form, be it accessible to new customers, providing new services to beneficiaries. The rural areas, as reported by Rural EU Review, are estimated to generate $48 \%$ of the gross value of the EU economy and $56 \%$ of total employment. A typical characteristic of the rural economy is the presence of small and medium enterprises (SMEs), many of them are micro-enterprises with a high percentage of selfemployment jobs. Innovations in rural and agricultural microfinance have significant potential to improve the livelihoods and food security of the poor. Although microfinance has been studied extensively, there is a big gap of knowledge, especially regarding the possibility of expanding access to rural and agricultural microfinance. In order to have a complete picture of how microfinancing works in rural Romania, we need to find out some facts about the technical infrastructure of data communications. Three out of four households in Romania have access to the internet after an increase of 30\% over the past six years, according to a Eurostat study, given that in 2016 the European average was $85 \%$ of households with access to network Internet home. "Between 2010 and 2016, Romania and Bulgaria registered the largest increases in the number of households with Internet access, but still remains among the countries with the lowest share in Europe," says the study Eurostat. A comparable level with the Romanian internet access is also recorded in Bulgaria, Greece and Lithuania, all less than $75 \%$. Opposite are Luxembourg, the Netherlands and Denmark, where nine out of ten households have Internet access and where growth rates in the period $2010-2016$ ranged between $6 \%$ and $7 \%$. The rate of those who have never used the internet decreased by about 20\% from 2010 to 2016 shows the results for Europe. However, in Romania and Bulgaria quarter of the population does not use the Internet. In Europe, more than one quarter of users use the Internet daily and the many users belong to the category of people with average or higher education and aged between 16 and 54 years. Internet is used most often for sending e-mails, to search for information or to read various publications. According to a European Commission report, Romanians used the internet for banking less in 2016 compared to 2015, and online businesses have sold slightly less. The figures are at least surprising considering the fact that banks reported a subscriber growth of remote trading services and e-commerce increased in 2016 by half a billion USD (without taking into account pay bills and insurance). The European Commission publishes an annual report on the progress of Member States in terms of digital integration. The report is based on an index called DESI (Digital Economy and Society Index), a composite index that measures the progress of digital according to five elements:

1. connectivity - fixed broadband, mobile broadband, the broadband speed and price;

2. Human capital - using the Internet, basic and advanced computer literacy;

3. Use of the Internet - using content by citizens, communication and online transactions;

4. integration of digital technology - digitalization of business and commerce;

5. digital public services - eGovernment. 
Romania has one of the highest proportions of subscriptions to high-speed broadband from the EU, and increasingly more people are using mobile broadband services. Although the available spectrum is growing, covering fixed and mobile networks $(4 \mathrm{G})$ broadband remains one of the lowest in the EU. Increasingly more people use the internet and the digital skills is growing, but it still ranks second lowest in the EU. Romania has a relatively high number of graduates in science, technology, mathematics and engineering. The Internet users from Romania carried out far fewer online activities than the EU average, in particular for e-commerce and e-banking. Social networks and online video calls, however, are extensively used. Romania is the largest country in southeastern Europe about the online audience, the number of Internet users is 8.8 mil. in December 2013, according to the report "Online Landscape in South-East Europe" made by Gemius. Traffic from mobile devices is growing fast on Romanian market. Thus, if in January 2013 only 3\% of Internet traffic is via mobile phones and tablets, in March 2014 this percentage rose to 7\%. Very interesting is the fact that while the rural population is almost nonbankable, the only institution that provides financial and banking services in villages of Romania being only CEC Bank and the Mail, 33\% of people living in rural areas access the internet. In other words, there is a great potential for service in regime of "distance banking". The question is - will know the microfinance institutions to exploit this potential? (e.g.: Natalia Plominska, Patrick Waledziack, 2013)

\section{Collecting financial network (RFC):-}

Within this network are mobilized availability of money from business entities that have capacities of funding. Financial instruments which are collected availabilities monetary deposits (DP) and securities (TV).

Both deposits and securities are diversified maturities, interest, ways etc. tailored bidders currency needs to exploit their advantage as availability. However, the two types of instruments have specific hedging techniques, to protect the interests of tenderers, risks arising from the economic environment, the banking entities and the investment vehicle used for "investing" cash collected.

\section{Within this network operates two categories of participants:-}

a). availability bidders (ODP), represented by households (GP), businesses (FR), State (ST) and even financial institutions (FIs). For methodological reasons we have not considered "outside", ie financial relations with subjects from abroad.

b). collecting financial institutions (IFC) which can be separated according to the two types of institutions collection (ISC): banks (IB) and non-banks (IN).

They are universal and specialized banking institutions (commercial banks, popular banks, savings banks, investment banks, etc.) defining characteristic being that the conversion of deposits into investment instruments (IPL), generating and money creation. At the same time, these institutions performed and cash receipts and payments in the economy.

This network of collection of deposits (PDP) is highly regulated and controlled mainly by the National Bank and banking institutions, balance supply and demand parameters have been established, usually by banks (both for shortterm deposits -PDZS - and for long-term deposits - PDZL)

Availability collect non-bank institutions using a variety of securities purchased by bidders liquidity, availability and places them investors, to those who need short-term liquidity. Disintermediation has triggered such a diversity of financial institutions, which have adapted their tools bidders needs. Such institutions are: insurance companies, pension funds, mutual funds, investment funds, securities companies, etc.

These institutions store their availability collected from banks, representing institutional deposits with funds managed by management companies specialized.

Financial network collection is divided into components differentiated in many respects, the main components are: subnet mutual funds (PFM), subnet insurance (PAS), subnet investment funds (PFI), subnet pension funds (PFP), subnet mortgage (PIC) and so on these components by connecting to financial institutions, network placements. Typically, this network constitutes institutional liquidity (LIT), capitalized strengthened through professional management of investments. 
A subnet distinct, specific network of financial collection is the subnet collection of the state (PCT), through which the state raises its financial resources (using Treasury - TPB) subnet is divided into two parts: subnet tax collection ( $\mathrm{PCF}$ ) and subnet public borrowing (GDP).

This distinction does not mean separation, segmentation, strict collection, banking institutions operating in the subnet securities, using financial instruments for attracting cash deposits (certificates of deposit). Also in this network act and Treasury, institution using financial instruments to borrow both from the public and from financial institutions, constituting often and warehouses.

Simplified financial network collector is shown in the following figure.

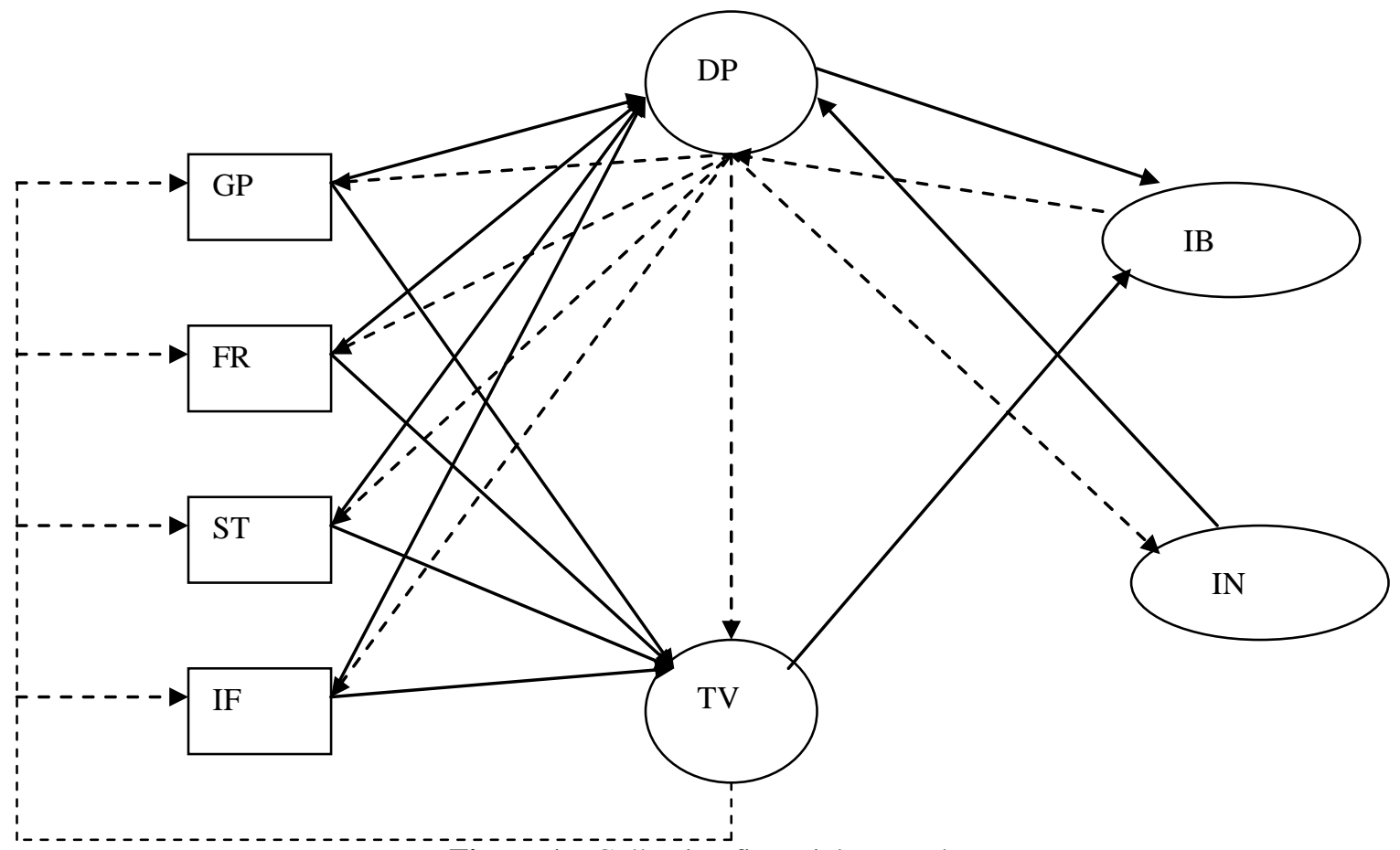

Figure 1:- Collecting financial network

Collecting financial network so presented that suggest a targeted networks:

$>$ From the offer to financial institutions, the cash collected by the latter (DSB);

$>$ Tenderers from financial institutions, the "price" of loans to deposits and debt securities, interest (DBZ). Cash flows collected as deposits and flows involves withdrawal from banking institutions by bidders, or conversion into securities.

This network represents institutional network (RID), which carries the solicitatorii cash drain of financial resources (SRF).

The interest is offered by debt securities and are distributed evident by banking flows.

To make sure we don't complicate the scheme, withdrawals are indicated by dotted lines.

We will make the following notations:

$(\mathrm{DSB})_{\mathrm{i}}=$ total availability collected from each bidder;

$(\mathrm{DSB})_{\mathrm{ij}}=$ availability collected by the two types of tools: DP şi TL;

$(\mathrm{DP})_{\mathrm{f}}=$ final existing deposits at banking institutions;

$\mathrm{DPD}=$ direct deposits of bidders;

DPI = institutionalized deposits of financial institutions;

DPT $=$ warehouses converted into securities;

$(\mathrm{RIC})_{\mathrm{k}}=$ remuneration of financial instruments collection;

$\mathrm{RNB}=$ remuneration non-interest financial securities collection;

$\mathrm{i}=1,2,3,4=$ tenderer $(\mathrm{GP} ; \mathrm{FR} ; \mathrm{ST} ; \mathrm{IF})$; 
$\mathrm{j}=1,2$ = forms of collection instruments (DP; TL);

$\mathrm{f}=1,2=$ final deposit categories (DPD; DPI);

$\mathrm{d}=1,2=$ financial institutions collectors through securities (IB şi IN);

$\mathrm{k}=1,2=$ forms withdrawal of deposits and securities.

Using the symbols above, can write the following relations:

$\sum_{i=1}^{4}(\mathrm{DSB})_{\mathrm{i}}=\mathrm{DST}$

where

DST $=$ total availability collected by financial institutions;

$\sum_{\mathrm{j}=1}^{2}(\mathrm{DSB})_{\mathrm{ij}}=(\mathrm{DSB})_{\mathrm{i}}$

$\mathrm{R}_{\mathrm{ij}}=\frac{(\mathrm{DSB})_{\mathrm{ij}}}{(\mathrm{DSB})_{\mathrm{i}}}$

where

$\mathrm{R}_{\mathrm{ij}}=$ collection rate by each financial instrument from each bidder.

$(\mathrm{DSB})_{\mathrm{j}}=\sum_{\mathrm{i}=1}^{4}(\mathrm{DSB})_{\mathrm{ij}}$

where

$(D S B)_{j}=$ availability collected by the $\mathrm{j}$ instrument.

$R_{j}=\frac{(D S B)_{j}}{\sum_{i=1}^{4}(D S B)_{i}}=\frac{(D S B)_{j}}{D S T}=\frac{\sum_{i=1}^{4}(D S B)_{i j}}{\sum_{i=1}^{4}(D S B)_{i}}$

$R_{j}=$ collection rate by the $j$ instrument.

$\mathrm{DPF}=\mathrm{DPD}+\mathrm{DPI}-\mathrm{DPT}=\sum_{\mathrm{i}=1}^{4} \sum_{\mathrm{j}=1}^{2}(\mathrm{DSB})_{\mathrm{ij}}=\sum_{\mathrm{i}=1}^{4}(\mathrm{DSB})_{\mathrm{i} 1}+\sum_{\mathrm{i}=1}^{4}(\mathrm{DSB})_{\mathrm{i} 2}$

$\mathrm{DPF}=$ final bank deposits.

$\mathrm{R}_{\mathrm{f}}=\frac{(\mathrm{DZ})_{\mathrm{f}}}{\mathrm{DPF}}$

where

$\mathrm{R}_{\mathrm{f}}=$ the rate of formation of deposits (direct or institutional).

$\mathrm{DBZ}=\sum_{\mathrm{l}=1}^{5}(\mathrm{DBZ})_{1}$

$\mathrm{DSB}_{\mathrm{j}=1}$ for $\mathrm{i}=1,2,3,4$;

where $1=\left\{\mathrm{DSB}_{\mathrm{j}=2 \text {. }}\right.$

It defines five categories of interest such (1): four related bidders "i" and one related to the bonds (TV).

$\mathrm{DPF}=\sum_{\mathrm{f}=1}^{5}(\mathrm{DPF})_{\mathrm{f}}=\sum_{\mathrm{i}=1}^{4} \sum_{\mathrm{j}=1}^{2}(\mathrm{DSB})_{\mathrm{ij}}$

$\mathrm{RIC}=\sum_{\mathrm{k}=1}^{2}(\mathrm{RIC})_{\mathrm{k}}$

when 


$$
\begin{aligned}
& \mathrm{k}=1 \rightarrow \mathrm{RIC}_{1}=\sum_{\mathrm{l}=1}^{5} \mathrm{DBZ}_{1} \\
& \mathrm{k}=2 \rightarrow \mathrm{RIC}_{2}=\sum_{\mathrm{i}=1}^{4} \mathrm{RTV}_{\mathrm{it}}
\end{aligned}
$$

where

$\mathrm{RTV}_{\mathrm{t}}=$ retribution of $\mathrm{t}$ securities.

So:

$$
\begin{aligned}
& \mathrm{RIC}=\sum_{\mathrm{l}=1}^{5}(\mathrm{DBZ})_{\mathrm{l}}+\sum_{\mathrm{i}=1}^{4} \mathrm{RTV}_{\mathrm{it}} . \\
& \mathrm{R}_{\mathrm{k}}=\frac{(\mathrm{RIC})_{\mathrm{k}}}{\sum_{\mathrm{i}=1}^{4}(\mathrm{DSB})_{\mathrm{jk}}}
\end{aligned}
$$

Formalizing financial network collectors can provide ways of determining the "charges" inadequate flows across their networks (availabilities, securities, deposits) and 'resistance' remuneration determined rates circuits managed uncorrelated. This way you can intervene to fine-tuning of network operations, through regulation.

\section{Network of financial placements (PPF):-}

Through this network is realized or mediated direct distribution of monetary resources collected by entities that need funding. Face potential supply demand, supply enabled by financial institutions. The financial instruments used are of two categories: loans (CR) and marketable securities (TPL).

The two categories of instruments are highly diversified and differentiated, tailored and demand conditions of liquidity, this diversification aimed at "prices" attached, including interest, risks that accompany differently each type of tool, risks arising from the beneficiary liquidity (investor) the nature of the instruments, the management of financial institutions, the economic environment for business etc. Diversification is generated by the agreed period, the procedures for reimbursement, the specific nature of financial institutions and clients, investors, liquidity destinations.

Loans and investment securities delimit distinct financial subnets regulated differently, sometimes two categories of tools are transformed into each other. 


\section{In this financial network operates two categories of participants:-}

a). financial institutions for placements (PFIs) which are usually collecting financial institutions (IFC), but manifests and other institutions only investment activities, investment financial institutions (IFIs), valuing them up or deposits funds in investment securities.

We can write the following relationship:

$a($ IFP $)=\mathrm{a}($ IFC $)+\mathrm{a}(\mathrm{IFI})=\mathrm{a}(\mathrm{IB})+\mathrm{a}(\mathrm{IN})$

where

a). Represents the flows in financial network of placements

b). The applicants for financial resources (SRF), which is real demand for financial resources to invest them, applicants are primarily companies (FR) and the State (ST), and households (GP) and financial institutions (FIs).

The relationship between banking institutions and non-banking financial institutions functional, subnet being interconnected segmented into two compartments - subnet loans (PCD) and subnet investment securities (PTL). However, it is a network unit, the two types of financial instruments are transformed into each other.

Subnet loans divides subnet interbank (PRP), the major component of the network supply (PMT), subnet credit economy (PCE), corresponding to overall loans to the economy, subnet public credits (PCB), subnet consumer loans (PCS), subnet credits mortgage (PCI) etc.

A separate subnet, subnet connected public credit (counterparty of public loans), a subnet is public investment (PIP) which the state places, in various forms, the necessary liquidity for the investments in the economy. This is part of the network subnet public investments (PDB).

Subnet investment securities (PTL) is divided in turn into actions subnet (CAP), ie property titles and subnet bonds (POB), both forming subnet securities (PVB), subnet short-term securities (PTT), etc.

Network financial investment is divided but not only after the nature of the instruments but also after the formation of their prices, representing initial core network (PPR), in which they sell securities by applicants liquidity, which become beneficiaries cash to liquidate Title, often with investor liquidation. Securities are purchased through financial institutions by liquidity supply, which may be financial institutions, which are investments in institutions (PLI), various so the private placements (PLP), the primary network dividing it from this point of view the primary network private placements (PPP) and the core network of institutional placements (PPI).

Securities acquired are then negotiated within the network side (PSC), supply and demand being generated by bidders to availability, which entered the subnet stock (PBS), institutionalized form of PSC, connect their differentiated financial resources, motivations being either protecting, gain, often speculative, of "propriety" etc.

Subnet investment securities generated a kind of risk, "distribution" with a speculative load special, often volatilizing securities values, values that become the object of transactions, naming the subnet subnet derivatives (PDV).

The two types of investment instruments often, as I said, is transformed into one another, especially loans becoming investment securities, recorded in this process of deleveraging, ie to reduce the flow of loans in favor of flows investment securities .

It identifies such a different subnet within the PPF, subnet transformation investments (PTP), under its securitization (PTR) is an essential component, these transformations carried out both types of loans between and among types of securities. This subnet is structural (PST) in PPF, changing the structure of investments.

Differences between the two components of the network are obviously financial investments beyond their interconnections.

Subnet loans, creating currency can be called a subnet extensional (PEX) is controlled and regulated by the National Bank and banks, the latter setting unilateral characteristics of loans, especially their price, interest rate, which reflects the "equilibrium" between supply and demand financial resources. Subnet investment securities is more open than the banking network, especially through component stock, supply and demand of funds more transparent 
price setting, usually interest, but a subnet is more risky, speculative, volatile. Specific network's institutional financial investment shown in the following figure simplified.

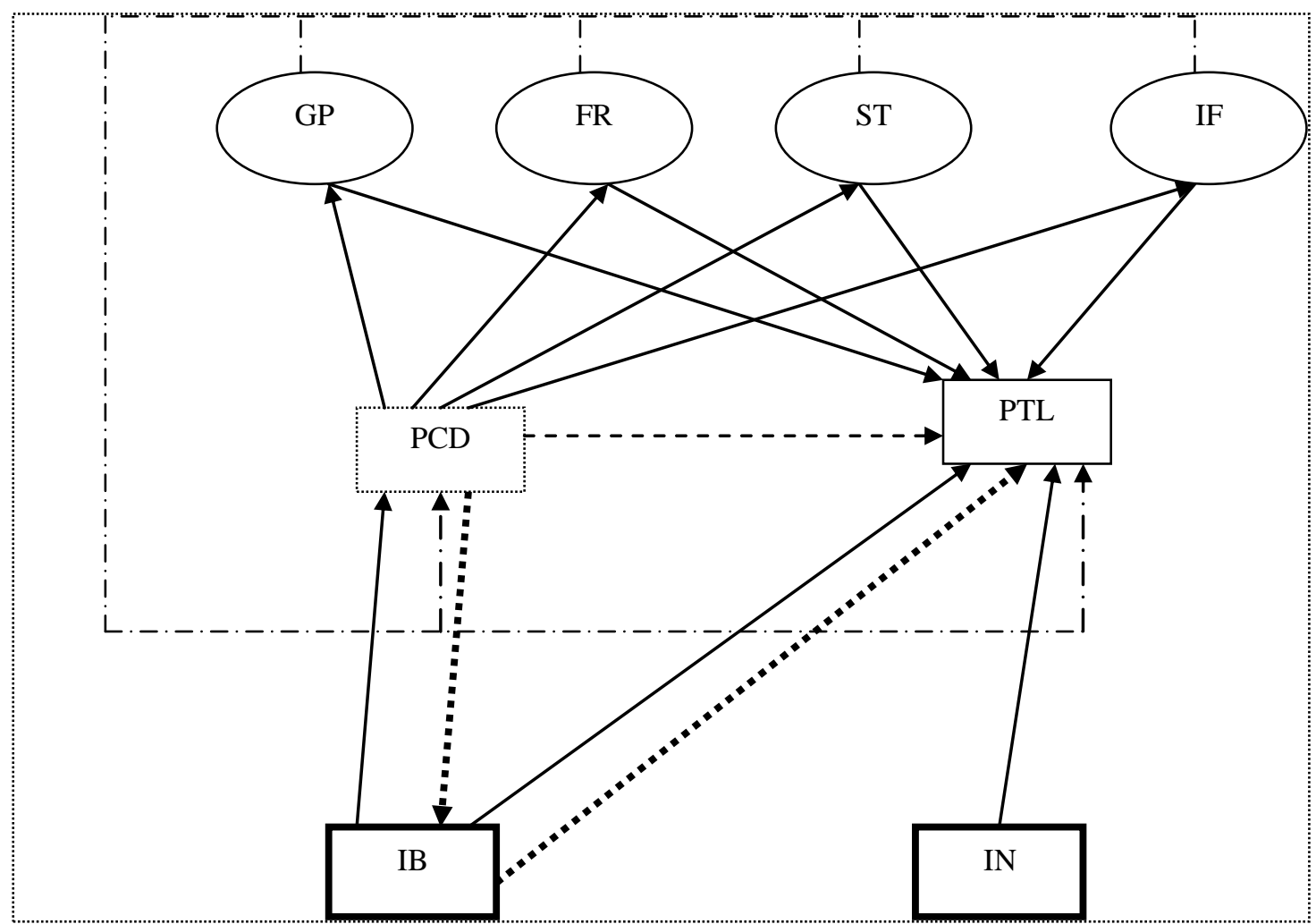

Figure 2:- Network of financial placements

Simplified scheme highlight the existence of two-way money flows oriented networks:

$>$ from financial institutions for applicants for financial resources, especially companies and state through loans and investment securities purchased in the name of bidders, the financial institution has collected;

$>$ since applicants of placements to financial institutions is realized cash flows that financial resources are returned only in terms of chargeability and also paid the prices of investment instruments.

Within the financial placements network, the central place it occupies banking institutions, because all money flows transited both on loans and investment securities (if their financial resources placed are in bank deposits) and prices of investment opportunities and returns financial resources.

We will make the following notations:

$(\mathrm{PLT})_{\mathrm{i}}=$ total placements from the perspective of each applicant.

$\sum_{\mathrm{i}=1}^{4}(\mathrm{PLT})_{\mathrm{i}}=$ PLT

where

PLT $=$ total placements, ie total financial resources procured by applicants.

From the perspective of placements instruments PLT is calculated as:

$\mathrm{PLT}=\sum_{\mathrm{r}=1}^{2}(\mathrm{PLT})_{\mathrm{r}}$,

where

$\mathrm{r}$ represents the two categories of placements instruments, loans and securities.

At the same time, total placements can be determined and the amount of placements of the two categories of financial institutions 
$\mathrm{PLT}=\sum_{\mathrm{m}=1}^{2}(\mathrm{PLT})_{\mathrm{m}}$

where

$\mathrm{m}=$ category of financial institution.

Total financial resources (RFT) obtained by each of the four types of applicants could be estimated as:

$(\mathrm{RFT})_{\mathrm{i}}=\sum_{\mathrm{m}=1}^{2}(\mathrm{PLT})_{\mathrm{mi}}=\sum_{\mathrm{r}=1}^{2}(\mathrm{PLT})_{\mathrm{ri}}$.

Obviously, it checks the relationship:

$\sum_{\mathrm{i}=1}^{4}(\mathrm{PLT})_{\mathrm{i}}=\sum_{\mathrm{i}=1}^{4}(\mathrm{RFT})_{\mathrm{i}}$

Based on these indicators can determine some significant rates for characterizing network voltages and resistances from institutional placements network (RIP).

$\mathrm{R}(\mathrm{PLT})_{\mathrm{i}}=\frac{(\mathrm{PLT})_{\mathrm{i}}}{\mathrm{PLT}}$

This rate expresses the load flows of financial resources of each applicant.

$\mathrm{R}(\mathrm{PLT})_{\mathrm{ir}}=\frac{(\mathrm{PLT})_{\mathrm{ir}}}{(\mathrm{PLT})_{\mathrm{i}}}$

where

$\mathrm{r}=$ placement tool used.

This rate reflects the distribution of financial resources the applicant on the two placements instruments.

$\sum_{\mathrm{i}=1}^{4} \sum_{\mathrm{r}=1}^{2} \mathrm{R}(\mathrm{PLT})_{\mathrm{ir}}=1$

Do the following notation:

RTP $=$ The total remuneration of placement instruments.

$$
\begin{aligned}
& \mathrm{RTP}=\sum_{\mathrm{r}=1}^{2}(\mathrm{RTP})_{\mathrm{n}}=\sum_{\mathrm{i}=1}^{4} \sum_{\mathrm{r}=1}^{2}(\mathrm{RIP})_{\mathrm{ir}} \\
& \mathrm{RIP}=\sum_{\mathrm{r}=1}^{2} \sum_{\mathrm{m}=1}^{2}(\mathrm{RIP})_{\mathrm{rm}} .
\end{aligned}
$$

The two relationships highlight the contribution of each applicant and the financial institution to total remuneration of placements.

Further note:

$\mathrm{CRT}=$ the total remuneration coefficient of placement instruments.

$$
\mathrm{CRT}=\frac{\text { RTP }}{\text { PLT }}=\frac{\text { RTP }}{\text { LCT }}=\frac{\sum_{i=1}^{n}(\text { RTP })_{i}}{\sum_{i=1}^{n}(\text { PLT })_{i}} .
$$

Depending on the analytical requirements of the network can be so detailed rates and coefficients and indicators.

Formalizing financial placements network provide ways of determining the "charges" flows across their networks (availabilities, securities, deposits) and 'resistance' remuneration determined rates circuits managed uncorrelated. As with financial market collectors using monitoring using indicators proposed, can intervene to fine-tune the operation of the market through regulation.

\section{Conclusions:-}

Demand for loans were and are today more than $93 \%$ of the rural population. Faced with this situation, we concluded that the only way to connect villages to the circuit of domestic economic market is the creation and 
generalization of specialized micro patterns or to provide to the rural households access to financial resources, especially through microfinance institutions. Encouraging is that Romania currently has already taken clear and concrete to support the approximately 830,000 smallholders. But there is always more to be done:

$\checkmark$ support and revive small-scale farming requires a comprehensive platform of political and developmental initiatives that are tailored to the unique needs of farmers and diverse family farms;

$\checkmark$ improving the access to land, water, markets and credit - as well as a legislation on the ownership and use of standardized land - creates a solid foundation for productivity, solid ground on which farmers can and will invest in the future of their farms;

$\checkmark$ public investment in rural infrastructure, public services, training and education can give small farmers the help they need to be competitive in a market increasingly globalized;

$\checkmark$ encourage women and youth to participate in agriculture will guarantee long-term viability of family farming.

Accepting the standard definition of risk as the probability of an event with adverse effects for economic issue, the risk of network financial area can be defined as the probability of occurrence, outbreak and after one incident network that may affect the achievement of favorable network features financial and its interactive flow. The risk is a risk of network flow, which disrupts, damages interconnectivity and interactivity of network elements, constituents, or transients distribuenţi having adverse effects fulfillment financial network characteristics.

Network risk exposure represents the potential value or actual losses arising from damage to these characteristics, measurable value directly or indirectly through reductions in expected revenues or increases in expenditure considered properly carried out under normal network features. Achieving adequate functional characteristics is that state network which ensures its aims fulfilling its conditions, conduct interactive streams to capitalize functions and potentialities forms of monetary financial assets by transferring financial and monetary instruments.

Approached in terms of the flows and network, explained above, also one of the possible perspectives, risk Network monetary manifests feature size institutive network, led by malfunctions occurred in the way it conducted the institutionalization of the network, its characteristics, network interactive fulfilled by financial market flows. If the market performs interactive content network financial market institutions, is shaped to achieve this content, dysfunctional form affecting content, the risk of network representing just within disturbances form, for example in regulating markets, network, regulatory understood as establishing rules functional on the reliability, network complexity or velocity, so its interactive flows.

Financial network realizes its goal defining, generic, dynamic balance between demand and supply of currency in market conditions institutionalized in which network elements are regulated, organized, coordinated, supervised, even controlled through a system of relations, attributes and differentiated responsibilities entities network system has rules and procedures for instruments and operations, leading market institutionalize quality network operation, network risk as a consequence of inadequate institutivităţi network.

According to the definition and delimitation of the above risk in financial area network has some distinctive features, the most relevant being:

* is a risk that disrupts the interaction with the network flows, affecting force interactivity, asset transfers, distributive and transitive element of the network, especially of its constituents, interactive network that gives individuality potentiality, finality;

* is a risk affecting the interconnectivity network connections, connections between elements, allowing and encouraging implementation of interactivity risk of decoupling, distortion, distortion, debilitating dephasing of these links, interconnectivity giving network coherence, consistency and validity; this feature is reflected, for example, by affecting interfaces and nodes, the financial center coupling and connection, monetary conversion operators etc.

* is a risk that manifests itself by altering the characteristics of flow and network at risk of authenticity network in anticipation of this research feature is bearing risk, risk, regardless of the characteristic altered induce damage interconnectivity and disruption of interactivity, reducing active capacity network to transfer and convert currency, monetary forms by distributing tools and transient operations;

* is a risk of tripping, accompanying and strengthening of risks specific to the monetary and financial, for example, reduced labor clotting network can trigger risks such as liquidity, shortage of funds, or, in another context, risk not recovered correlated with the course, can also strengthen financial risks caused by internal or external environment of an entity or inadequacy of the financial instrument; 
* is a risk of the spread, the contagion of perpetuating all risks specific to the financial, for example, network disengaged increasing the likelihood and extent of the risk of interest rate or insolvency, contagion assuming, however, generation by disrupting interactivity specific risks favoring inclination and preference for risk of network entities;

* is a risk arising from the embodiment of interactivity the way of establishing interconnectivity financial space, ie a specific hazard of institutions, rules, manifest markets, network interactivity.

* This feature highlights network risk that as a human creation, even if it is determinative social financial network constitute the institutional forms, and in this respect, the risk of network failures is caused by the embodiments of the financial network.

* Obviously, in light of this research, that this is the defining characteristic, but not essential for risk in the financial network.

* Action risk network of space Financial is mediated by specific risks of this space, the risk of network generated, as I said, malfunctions institution is perceived by the impact of one or more specific risks induced by the emergence and manifestation risk network its concrete shape, as determined by the affected network feature. In this respect, the risk action network reveals that act to enhance the propagation of specific risks.

* This bias is achieved through three channels: Channel incompleteness configurationnal, and insufficient organizational incompleteness of the network, its entities, the network is unable to achieve monetary transfer forms, financial instruments in accordance with the aims and its potentialities. Incapacizarea can be constitutive entities, driven by its attributes organizational or topology Configuration, which was endowed regulatory, institutional, or be a incapacizare inductive induced environment, the monetary system, for connections to other economic systems and social. For example, one segment of the financial market, the bond market can boost the risk of interest rate due incapacizării banks to conduct money creation sufficient to incapacizării business entities to achieve savings needed, or firms to cover part significant financing needs from its own resources, organizational character of incapacizării on the format constituent entities: bank deposit insufficient population occupational unstructured, non-oriented companies to the market. In addition, the network might not have the distribution nodes and links of sufficient or adequate interfaces with the environment, with customers.

* Channel inadequate network of inconsistency compositional and nereprezentativităţii streams interactive, network Not having the instruments and forms of currency appropriate, and also flows transfer their interactivity not reflecting enough or reflecting deformed inauthentic actual demand for money transfers through instruments available. In this respect, for example, lack or shortage of trade credit instruments, weak institutional and expansion of non-banking financial flows, such as mutual funds can help the emergence risk of blockage and bankruptcy.

* Channel of inactivity of network, of dephasing operational and disconnection of circuits, network operating often incorrect, invalid transfers of currency, ie without justification or sufficient coverage of risk, and failing to ensure the achievement compatible to all streams of the complete circuit of the forms of monetary or financial instruments manifestation specific risks this channel is obviously facilitated by the action of the other two channels of interactivity, Configuration, and the interactions, compositionally.

* Favoring through three channels, spread risks specific monetary system, network risk, its concrete forms, adverse effects, generating net losses and claiming cost recovery, rehabilitation financial network.

* The risk of network effects can be separated into the following categories complementary:

- Indirect effects induced by disfuncţinalităţile institutional, through specific risks network financial flows interactive, influencing their performance, affecting the value forms monetary validity of financial instruments, their potential to maintain and multiply the value, in other words, yes to achieve the transfer currency buyers bidders from savers to those who invest. These types of effects cover a variety of distinct effects, generating losses and costs, such as depreciation forms currency, the bankruptcy of some financial entities, volatilization of financial instruments, eg shares, participation certificates, diversion of liquidity, etc.

\section{References:-}

1. Costa Arjuna, Deb Anamitra, and Kubzansky Michael (2014), Big Data, Small Credit. The Digital Revolution and Its Impact on Emerging Market Consumers;

2. Dimitriu Mihail, Manta Otilia, (2017), Architecture of flows and financial stocks (Mechanism and transmission channels, flow, transmitters and receivers);

3. Frydrych Jennifer and AschimHege (2014), Extending reach: Mobile money in rural areas. Findings based on the State of the Industry Report; 
4. Froot, Kenneth, and Paul O'Connell (2003),“The Risk Tolerance of International Investors.” NBER Working Paper No. 10157;

5. Manta, Otilia (2015), Microfinance, active factor in the social and financial inclusion;

6. Manta, Otilia (2016), The role of microfinance in sustainable rural development;

7. Manta, Otilia (2016), Financing instruments in eradicating poverty;

8. Misina, Miroslav (2003), "What Does the Risk Appetite Index Measure?"Working Paper No. 2003-23, Bank of Canada;

9. Plominska Natalia, Waledziack Patrick (2013), Online Landscape, South - East Europe, Gemius;

10. Tarashev, Nikola, Kostas Tsatsaronis, and Dmitrios Karampatos (2003), "Investors' Attitude Towards Risk: What Can We Learn from Options?” BIS Quarterly Review (June):57-66.

11. Accenture Banking, Beyond the Everyday Bank. How a GAFA approach to digital banking transformation will increase revenues, improve customer engagement, while reducing the cost base, 2016;

12. Accenture Financial Services, Financial Services: transforming distribution models for theevolving consumer, 2017

13. European Network for Rural Development, EU Rural Review N 13, 2012

14. European Network for Rural Development, EU Rural Review n. 10, 2011 